\title{
A Modeling System of Nutrient Loads to Long Island Sound from Connecticut Watersheds
}

\section{J. T. Love and A. S. Donigian, Jr.}

Over the past fifteen years, state and federal efforts have focused on improving the water quality and natural resources of Long Island Sound (LIS), with a specific emphasis on addressing the issue of hypoxia. A comprehensive multiphase management plan under the LIS Study (LISS) aims to reduce nitrogen loads entering the Sound.

In this study, funded by the United States Environmental Protection Agency (U.S. EPA) and the Connecticut Department of Environmental Protection (CT DEP), a statewide watershed model was developed as a tool to help quantify all sources of key nutrients to LIS, using the U.S. EPA Hydrological Simulation Program - FORTRAN (HSPF) and the U.S. Geological Survey's (USGS) graphical user interface GenScn. The Connecticut Watershed Model (CTWM) was developed to evaluate nutrient sources and loadings. It evolved by first performing calibration and validation on three small test watersheds across the state, and was then extended to three major river calibration basins and subsequently expanded to a statewide model, by using the most spatially applicable set of calibrated watershed parameters in non-calibrated areas.

Based on urban growth rates predicted to occur by the year 2020, buildout scenarios and resulting loads to LIS were developed for the six management zones. To evaluate potential impacts of alternative best management practices (BMPs), pollutant removal efficiencies were extracted from the literature, and composite pollutant removal efficiencies were estimated for BMPs relevant to both urban and agricultural lands. Alternative levels of BMP implementation

Love, J. and T. Donigian. 2002. "A Modeling System of Nutrient Loads to Long Island Sound from Connecticut Watersheds." Journal of Water Management Modeling R208-11. doi: 10.14796/JWMM.R208-11.

(C) CHI 2002 www.chijournal.org ISSN: 2292-6062 (Formerly in Best modeling practices for Urban Water Systems. ISBN: 0-9683681-6-6) 
were represented by defining increasing fractions of the urban and agricultural areas served by BMPs. Ultimately, three nonpoint source BMP implementation scenarios were developed and simulated, in addition to the buildout scenario with and without BMPs; and the associated nutrient reductions were evaluated. The user-friendly interface and framework of the CTWM was specifically designed to promote continuing use by CT DEP staff to assess additional BMPs, implementation levels, and relative impacts of point source controls for nutrient reductions to LIS.

\subsection{Introduction}

\subsubsection{Background and Objectives}

In 1985, the LISS was begun when Congress appropriated funds for the U.S. EPA to carry out a program to research, monitor, and assess the water quality of LIS in concert with the CT DEP and the New York State Department of Environmental Conservation (NYSDEC). As part of the Clean Water Act (CWA) Amendments of 1987, the National Estuary Program was established, and at the request of the states of both Connecticut and New York, LIS was designated an 'Estuary of National Significance' under this program (NYSDEC and CT DEP, 1999). Since that time, the ongoing study, conducted as a joint effort between EPA, CT DEP, NYSDEC, and a broad coalition of academic, consulting, and public interest organizations, has identified periodic hypoxia, especially in the western portions of the Sound, as a critical issue in need of management.

The issue of hypoxia, usually defined as levels of DO less than $3.0 \mathrm{mg} / 1$, has been the focus of the development of a comprehensive multi-phase management plan under the LISS to reduce nitrogen loads entering the Sound. The hypoxia condition results from high concentrations of nitrogen in LIS promoting excessive growth of algae, combined with the naturally occurring density stratification of the water column. When these algae die, they decompose, consuming oxygen in the process and leading to the hypoxic, or low DO conditions, and occasionally even anoxic (zero DO) conditions. The hypoxia in LIS typically occurs during the late summer months, adversely affecting the habitat for shellfish, juvenile fish, and invertebrates. The LISS has estimated that the load of nitrogen delivered to LIS has more than doubled since pre-colonial times, and that discharges from sewage treatment plants, atmospheric deposition, and nonpoint runoff are the primary sources of nitrogen enrichment to LIS (NYSDEC and CT DEP, 1999). 
The most recent phase of the comprehensive management effort adopted nitrogen reduction targets of $58.5 \%$ for eleven management zones that comprise the CT and NY portion of the LIS watershed. The plan, adopted by EPA, CT, and NY, includes a commitment to administer and enforce the nitrogen reduction targets through development of a total maximum daily load (TMDL) analysis, needed to achieve DO water quality standards, consistent with the requirements under Section 303(d) of the CWA (NYSDEC and CT DEP, 1999). In addition, the TMDL process also requires the states of Connecticut and New York to identify appropriate point and nonpoint source management options, in conjunction with the affected parties (e.g. municipalities and industry), that can meet the $58.5 \%$ nitrogen reduction target, and allow for review and revision every five years (NYSDEC and CT DEP, 1999).

Of the eleven nitrogen management zones contributing to LIS, Figure 11.1 shows the six zones primarily located within Connecticut. These management zones follow existing natural basin boundaries and thus, are amenable to watershed or basin-wide planning efforts needed to address the nitrogen reduction goals. Nutrient loadings from watersheds within the state of Connecticut are thought to be a significant portion of the total loads to LIS, and thus they are likely to have a significant impact on the water quality and aquatic health of LIS.

This chapter reports on a study to provide a watershed modeling framework for both (i) estimating the nutrient loads from the six Connecticut management zones, and their delivery to LIS, and (ii) evaluating the potential of alternative management options to provide the reductions needed to achieve the DO water quality standard in LIS. In line with this goal, the specific objectives of this study are stated as follows:

- quantify the sources of key nutrients within each designated geographic management zone or basin within the State of Connecticut and evaluate their delivery efficiency to Long Island Sound;

- generally identify appropriate nonpoint source management options within each zone; and

- identify, acquire and compile appropriate data within the framework of a watershed model that will allow the evaluation of loads and delivery analysis of selected nutrient management options and other variables.

Although the primary focus is on nitrogen, deemed to be the limiting nutrient for LIS, phosphorous and carbon loadings are also important nutrients due to their importance in aquatic nutrient cycles, their impacts on algal growth, and the resulting processes and mechanisms controlling delivery to LIS.

In meeting the above objectives, the CTWM (AQUA TERRA Consultants 


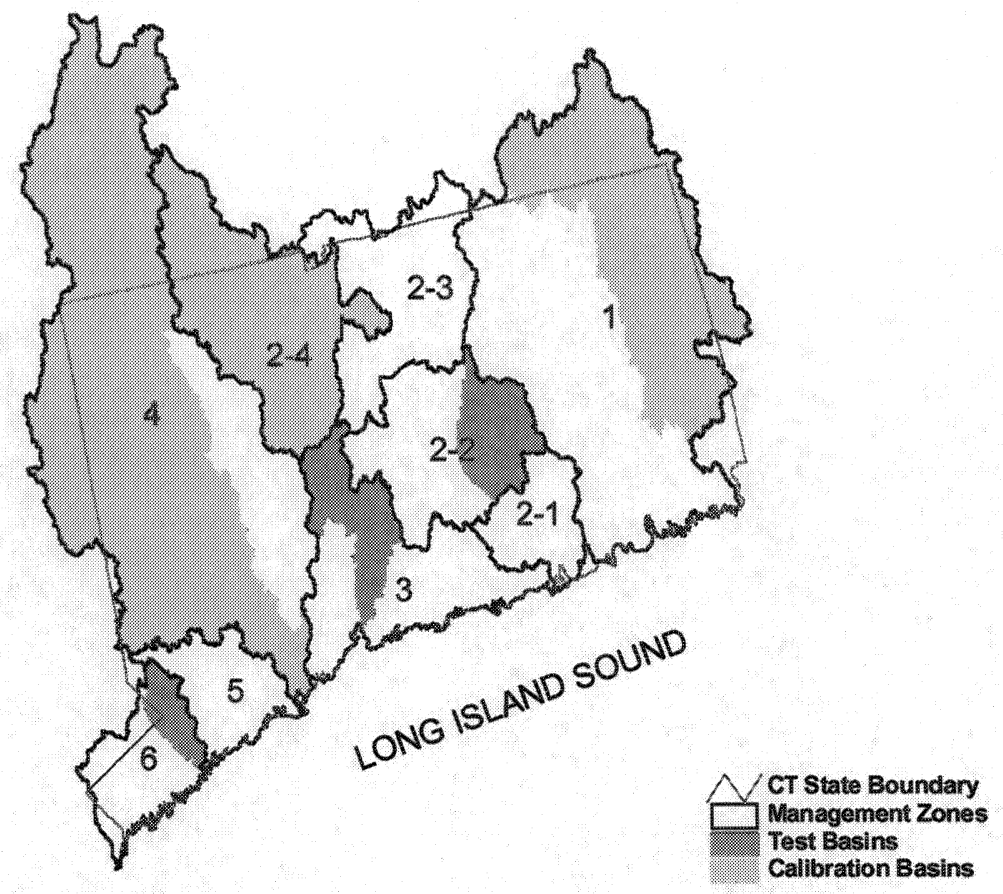

Figure 11.1 Nutrient management zones within the Connecticut Watershed Model.

and HydroQual, Inc., 2001), developed in this effort, can serve as a tool for the ongoing TMDL process by providing the framework for evaluating the impacts of alternative management options, analyzing potential tradeoffs between point and nonpoint loads, and performing the periodic reviews and revisions required by the regulation.

\subsubsection{Model Selection}

The development of a watershed model of nutrient loadings to Long Island Sound from Connecticut watersheds was patterned after the U.S. EPA Chesapeake Bay Program (CBP) Study. The U.S. EPA Hydrologic Simulation Program-FORTRAN(HSPF) (Bicknell et al., 1997, 2000; Donigian et al., 1995) is the framework for the CBP Watershed Model used to generate nutrient loadings, and investigate the impacts of alternative management strategies, to 
the Chesapeake Bay and as inputs to the hydrodynamic/water quality model being used to assess Bay water quality impacts (Linker et al., 1993; 1996).

The use of HSPF as the watershed model for the CBP Study has confirmed its ability to estimate nutrient loads and delivery from watershed areas; calculate contributions from point, nonpoint, and atmospheric sources; and provide a means of evaluating impacts of alternative management strategies to reduce nutrient loads and improve water quality conditions. In addition, HSPF is currently being used for watershed studies with similar objectives in Minnesota, Washington State, Oregon, Kentucky, South Carolina, Nevada, Florida, and Australia. Consequently, HSPF was selected as the watershed model framework for this study.

\subsubsection{Modeling Approach}

In order to address the study objectives, the Connecticut statewide watershed model was developed using the U.S. EPA HSPF, and the USGS graphical user interface (GenScn). HSPF provides all the capabilities needed to represent the nutrient loads to LIS from the six Connecticut management zones. GENeration and analysis of model simulation SceNarios (GenScn - Kittle et al., 1998) was developed to create simulation scenarios using HSPF, analyze the results of the scenarios, and compare scenarios. The development of the scenario generator came as a response to make HSPF input sequences easier to build and HSPF input/output time series easier to analyze. GenScn provides a user-friendly framework for HSPF applications and evaluating the impacts of alternative management options.

The CTWM was developed to evaluate nutrient sources and loadings within each of six nutrient management zones that lie primarily within the state of Connecticut, and assess their delivery efficiency to LIS. The CTWM evolved by first performing calibration and validation on three small test watersheds across the state (Norwalk, Quinnipiac, and Salmon) representing a range of land uses, including urban, forest, and agriculture. The model was then extended to three major river calibration basins (Farmington, Housatonic, and Quinebaug) and subsequently expanded to a statewide model by using the most spatially applicable set of calibrated watershed parameters in the non-calibrated areas. Figure 11.1 shows the locations of both the test watersheds and the major calibration basins; the calibration sites were chosen to provide good spatial coverage for the entire state.

A limitation of the HSPF model is that it cannot model estuaries nor tidallyimpacted stream segments. Thus, in order to assess the delivery efficiency of the watershed model loads for the lower portions of the major rivers, the System-Wide Eutrophication Model (SWEM), coupled hydrodynamic/water 
quality model, developed for the New York City Department of Environmental Protection, is used (HydroQual, 1999). SWEM was applied to the mainstem of Connecticut River, since it is tidal for essentially its entire length within the state limits, and the Quinnipiac and Housatonic river estuaries. The focus of the SWEM application was to develop 'attenuation factors' for the nutrient loads to represent the efficiency of each estuary to deliver the watershed loads to LIS. These attenuation factors are then used in a simplified assessment tool (spreadsheet) to apply the same factors for each alternative watershed scenario of management practices. For additional discussion on the SWEM model and assessment tool, refer to the complete Modeling Nutrient Loads to Long Island Sound from Connecticut Watersheds, and Impacts of Future Buildout and Management Scenarios report (AQUA TERRA Consultants and HydroQual, Inc., 2001).

The major steps in any watershed modeling effort include the following:

1. simulation plan development;

2. database development;

3. watershed segmentation and parameter estimation;

4. hydrology/water quality calibration and validation; and

5. simulation of alternative management scenarios.

These steps were followed in the development of the CTWM, in addition to the modeling of the delivery efficiency, or attenuation factors, using the extension of the SWEM for the Connecticut River, Housatonic, and Quinnipiac estuaries.

Once a model has been calibrated and validated, it can then be used for analyzing alternative conditions on the watershed as a tool for management purposes. The focus of this effort was to jointly assess possible future conditions and remediation alternatives, such as best management practices (BMPs), for the Connecticut watershed loads to LIS. Based on urban growth rates predicted to occur by the year 2020, buildout scenarios and resulting loads to LIS were developed for the six management zones. To evaluate potential impacts of alternative BMPs, pollutant removal efficiencies were extracted from the literature for BMP categories determined to be technically feasible and effective at removing the pollutants of concern. Composite pollutant removal efficiencies were estimated to correspond to the range of expected efficiencies for the categories of BMPs applicable for both urban and agricultural lands. Alternative levels of BMP implementation were represented by defining increasing fractions of the urban and agricultural land uses within each watershed as areas served by BMPs. Ultimately, three nonpoint source BMP implementation scenarios, representing $10 \%, 30 \%$, and $50 \%$ implementation were developed and simulated, in addition to the 2020 buildout scenario, with and without BMPs; and the associated nutrient reductions were evaluated. 


\subsection{Database Development for Watershed Modeling}

\subsubsection{Overview of Watershed Model Data Needs}

Data requirements for HSPF are extensive, in both spatial and temporal detail, especially for a Connecticut state-wide watershed model representing complex multi-land use watersheds and subwatersheds totaling more than $12,950 \mathrm{~km}^{2}$ $\left(5,000 \mathrm{mi}^{2}\right)$ of area. These data requirements can be categorized as either input/ execution data, watershed/channel characterization data, or calibration/validation data. Database development was a major portion of the total modeling effort, requiring acquisition of data from a variety of sources, developing estimation procedures when needed data were not available, applying available techniques to fill in missing data, and ensuring consistency and accuracy of the information obtained from often disparate sources. (See the complete study report (AQUA TERRA Consultants and HydroQual, Inc., 2001) for details.)

\subsubsection{Calibration/Validation Data}

The calibration and subsequent validation of watershed models requires observed values of the model state variables over a wide range of environmental conditions and other variables. These values are compared with model computations, and model parameters are adjusted to improve agreement during the calibration step. Measured values of the following were needed for as many observation sites as possible for the waterbodies being modeled:

1. flow,

2. temperature

3. dissolved oxygen (DO),

4. BOD and/or total organic carbon (TOC),

5. $\mathrm{N}$ species (e.g. $\mathrm{NO}_{3}, \mathrm{NH}_{3}$, organic $\mathrm{N}$ ),

6. $\mathrm{P}$ species (e.g. $\mathrm{PO}_{4}$, organic $\mathrm{P}$ ), and

7. chlorophyll a (representing phytoplankton)

This list is essentially the list of CTWM state variables, and the ones involved in the calibration/validation steps. The calibration and subsequent validation of the CTWM relied on observed data from USGS gages throughout the state.

Observed flow data were obtained from the United States NWIS-W data retrieval system at http://waterdata.usgs.gov/nwis-w/CT/. Water quality data were obtained from the National Water Data Storage and Retrieval System (WATSTORE) and Water-Data Reports for Connecticut. The WATSTORE retrieval was conducted by USGS personnel at the East Hartford office. Once 
obtained, all timeseries information were placed in the Watershed Data Management (WDM) file, the repository used by HSPF and GenScn. Figure 11.2 displays the locations of the stations.

\subsubsection{Streamflow and Water Quality}

Most of the flow data were used in the calibration and validation of test watersheds and major basins. Supplemental flow data were obtained for areas where parameters were extrapolated (i.e. non-calibration areas) to ensure the parameter extrapolation resulted in an accurate hydrologic response being simulated.

Water quality data were obtained for fourteen USGS gages throughout the state. These gages were used for calibration and validation of test watersheds and major basins and to a lesser extent validation of model performance in noncalibrated areas.

\subsubsection{Final Statewide Model Segmentation}

The purpose of watershed segmentation is to divide the study area into individual land and channel segments that are assumed to demonstrate relatively homogenous hydrologic/hydraulic and water quality behavior. This segmentation provides the basis for assigning similar or identical input and/or parameter values or functions to a land area or channel length contained within a segment. Since HSPF and most watershed models differentiate between land and channel portions of a watershed, and each is modeled separately, each undergoes a segmentation process to produce separate land and channel segments that are linked together to represent the entire watershed area.

Watershed segmentation is based on characteristics of the watershed, including topography, drainage patterns, land use distribution, meteorologic variability, and soils conditions. The process is essentially iterative, overlaying these data layers and identifying portions of the watershed with similar characteristics. Over the past decade, the advent of geographic information systems (GIS), and associated software tools, combined with advances in computing power, has produced automated capabilities to efficiently perform the data-overlay process.

The channel network consists of primary rivers and major tributaries along with major lakes and impoundments. The network is broken down into discrete segments based on spatially dependent characteristics. These characteristics include:

1. location of gage/data recorders,

2. location of channel junctions, 


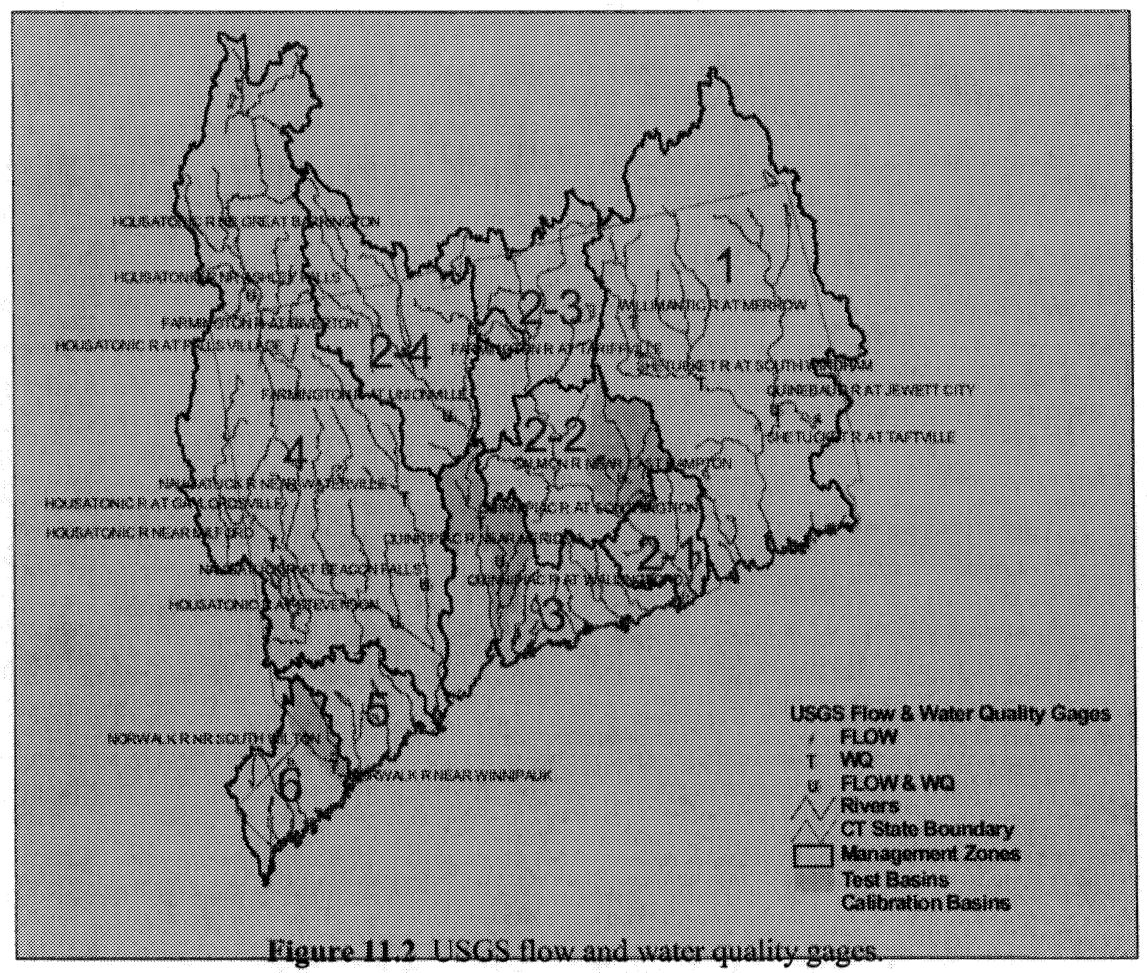

3. channel and floodplain characteristics (e.g. slope, roughness),

4. morphology obstructions (e.g. dams), and

5. location of point source discharges and diversions.

The stream segments should be short enough to reduce numerical dispersion and allow for better evaluation of local water quality by more accurately representing the location of point and nonpoint sources. However, the stream segments should be long enough that the residence time in the respective reach exceeds the simulation timestep. Ultimately, portions of the watershed that demonstrate a similar hydrologic and water quality response as well as sections of the stream channel with similar morphology and hydraulic behavior are grouped together.

\subsection{Overview of CTWM Calibration/Validation}

The period of calibration (1991-1995) and hydrologic validation (1986-1990) of the CTWM represented the most recent time period for which the required input/execution data and calibration/validation data were available and represented 
a wide range of hydrologic conditions. Comparisons of simulated and observed state variables were performed for daily, monthly, and annual values, in addition to flow-frequency duration assessments. Statistical procedures included error statistics and correlation coefficients.

For water quality and biotic constituents, model performance during the calibration period was based primarily on visual and graphical presentations, as the frequency of observed data was inadequate for accurate statistical measures. However, simple statistics such as annual maxima, minima, and mean were calculated and compared for simulated and observed concentrations. In addition, simulated nutrient loads delivered to LIS were compared with published values.

Quantitative criteria for model calibration/validation, sometimes referred to as model performance criteria, have been contentious topics in the environmental modeling community for more than 20 years. Unfortunately, there is still no general consensus on what constitutes a quantitative level of acceptance for model validation. However, as listed in Table 11.1, general calibration/validation tolerances or targets have been provided to model users as part of HSPF training workshops over the past 10 years (e.g. Donigian, 2000).

Table 11.1 General calibration/validation tolerances or targets.

\begin{tabular}{|c|c|c|c|}
\hline & \multicolumn{3}{|c|}{$\%$ Difference Between Simulated and Recorded Values } \\
\hline & Very Good & Good & Fair \\
\hline Hydrology/Flow & $<10$ & $10-15$ & $15-25$ \\
\hline Sediment & $<20$ & $20-30$ & $30-45$ \\
\hline Water Temperature & $<7$ & $8-12$ & $13-18$ \\
\hline Water Quality/Nutrients & $<15$ & $15-25$ & $25-35$ \\
\hline Pesticides/Toxics & $<20$ & $20-30$ & $30-40$ \\
\hline
\end{tabular}

The Table attempts to provide some general guidance, in terms of the percent mean errors or differences between simulated and observed values, so that users can gage what level of agreement or accuracy (i.e. very good, good, fair) may be expected from the model application. Individual events or observations may show larger differences. In addition, the level of agreement to be expected depends on many site- and application-specific conditions, including the data quality, purpose of the study, available resources, and available alternative assessment procedures that could meet the study objectives.

For the CTWM development effort, due to both resource and data limitations, the focus of calibration and validation efforts was primarily at the monthly and annual level of comparison for both hydrology and water quality. 
This was further supported by the study objective of providing nutrient loads for assessment of their impact on hypoxia, which is not highly sensitive to daily load fluctuations. Thus, the tolerances shown in Table 11.1 were adopted for this effort, as applied to monthly and annual hydrology, water temperature, and water quality/nutrients model results, as a means to evaluate the acceptability of the CTWM.

\subsubsection{Hydrology Calibration/Validation}

Comparisons of simulated and observed flow were performed during the calibration and validation periods for daily, monthly, and annual values, as well as flow-frequency duration assessments. In addition, the input and computed water balance components (e.g. precipitation, runoff, evapotransipiration) were reviewed for the individual land uses. Although observed values are not available for each of the water balance components, the average annual values must be consistent with expected values for the region, as impacted by the individual land use categories. This is a separate consistency, or reality, check with data independent of the modeling (except for precipitation) to insure that land use categories and overall water balance reflect local conditions.

Calibration of the CTWM was a cyclical process of making parameter changes, running the model and producing the aforementioned comparisons of computed and observed values, and interpreting the results. This process was greatly facilitated with the use of the of HSPEXP, an expert system for hydrologic calibration, specifically designed for use with HSPF, developed under contract for the USGS (Lumb et al., 1994). This package gives calibration advice, such as which model parameters to adjust and/or input to check, based on predetermined rules, and allows the user to interactively modify the HSPF Users Control Input (UCI) files, make model runs, examine statistics, and generate a variety of plots. The postprocessing capabilities of GenScn (e.g. listings, plots, statistics, etc.) were also used extensively during the calibration/ validation effort.

As previously noted, the primary objective of the CTWM was to provide loadings to LIS for the analysis of hypoxia. Prior studies had shown that nutrient loadings throughout the year contribute to the pool of nutrients available for uptake by phytoplankton; and the ultimate decay of that phytoplankton, resulting in hypoxia, was not sensitive to short term nutrient loadings(HydroQual, 1996). Thus, the hydrology calibration focused primarily on the monthly agreement of simulated and observed values as opposed to individual storm events.

Table 11.2 shows the agreement between simulated and observed mean annual flow at the test watershed and major calibration basin sites, along with 
Table 11.2 Summary of CTWM hydrologic calibration/validation - annual flow and correlation coefficients.

\begin{tabular}{|c|c|c|c|c|c|c|c|c|c|}
\hline & & \multicolumn{4}{|c|}{ Calibration Period (1991-1995) } & \multicolumn{4}{|c|}{ Validation Period (1986-1990) } \\
\hline Station Name & $\begin{array}{c}\text { Station } \\
\text { Number }\end{array}$ & $\begin{array}{c}\text { Mean } \\
\text { Observed } \\
\text { Annual } \\
\text { Flow } \\
\text { (inches) }\end{array}$ & $\begin{array}{c}\text { Mean } \\
\text { Simulated } \\
\text { Annual } \\
\text { Flow } \\
\text { (inches) }\end{array}$ & $\begin{array}{c}\mathrm{R} \\
\text { Average } \\
\text { Daily }\end{array}$ & $\begin{array}{c}\mathrm{R} \\
\text { Average } \\
\text { Monthly }\end{array}$ & $\begin{array}{l}\text { Mean } \\
\text { Observed } \\
\text { Annual } \\
\text { Flow } \\
\text { (inches) }\end{array}$ & $\begin{array}{c}\text { Mean } \\
\text { Simulated } \\
\text { Annual } \\
\text { Flow } \\
\text { (inches) }\end{array}$ & $\begin{array}{c}\mathrm{R} \\
\text { Average } \\
\text { Daily }\end{array}$ & $\begin{array}{c}\mathrm{R} \\
\text { Average } \\
\text { Monthly }\end{array}$ \\
\hline \multicolumn{10}{|l|}{ Test Watershed Gages } \\
\hline Salmon River nr East Hampton & 01193500 & 23.6 & 24.4 & 0.83 & 0.92 & 26.3 & 25.8 & 0.79 & 0.92 \\
\hline Quinnipiac River at Wallingford & 01196500 & 26.3 & 26.4 & 0.82 & 0.94 & 29.0 & 28.3 & 0.71 & 0.91 \\
\hline Norwalk River at South Wilton & 01209700 & 21.4 & 21.7 & 0.84 & 0.93 & 25.9 & 25.2 & 0.75 & 0.91 \\
\hline \multicolumn{10}{|l|}{ Major Basin Gages } \\
\hline Quinebaug River at Jewett City & 01127000 & 23.8 & 23.6 & 0.82 & 0.93 & 27.2 & 24.7 & 0.86 & 0.95 \\
\hline Farmington River at Tariffville & 01189995 & 26.2 & 26.0 & 0.85 & 0.92 & 26.2 & 29.1 & 0.87 & 0.94 \\
\hline Housatonic River at Stevenson & 01205500 & 31.7 & 31.9 & 0.88 & 0.98 & 34.6 & 31.5 & 0.87 & 0.96 \\
\hline
\end{tabular}


the correlation coefficients ( $\mathrm{R}$ values) for both daily and monthly timesteps. Based on the entire 'weight-of-evidence' of the full range of model results the hydrology component of the CTWM was deemed to be calibrated and validated, and to provide a sound basis for water quality. (See the complete study report (AQUA TERRA Consultants and HydroQual, Inc., 2001) for additional details.)

\subsubsection{Water Quality Calibration/Nalidation}

CTWM represents the various forms of nitrogen and phosphorus, their interactions and transformations, and other associated parameters or constituents (e.g. DO, BOD, water temperature). In addition, carbon loads are represented because of their contribution to the hypoxia problem in the Sound, and because source management controls for nitrogen will also control or remove a portion of the carbon load (NYSDEC and CT DEP, 1999). The sources currently considered include point sources, nonpoint sources from watershed land uses, and atmospheric deposition. Nonpoint loadings are calculated in the CTWM by considering accumulation and depletion/removal, and a first-order washoff rate of the available constituent removed by overland flow. Quantities in the subsurface outflow are simulated using a monthly varying concentration. The resulting nonpoint source loadings, calculated separately for each land use, are input to the channel reaches represented in the CTWM, along with the identified point sources, and the channel reaches compute the fate, transport, and delivery of the nutrient loads to LIS. Atmospheric deposition is imposed on all the land areas and provides a contribution to the nonpoint source load through the runoff/washoff process; direct deposition onto water surfaces represented in the model is also considered as a direct input to the river systems.

Once all nutrient contributions from all land uses are estimated, the modeled hydrologic and hydraulic processes are superimposed to provide transport mechanisms, and then water quality modeling is performed to allow adjustments in parameters and evaluation of sources as part of the calibration process. Nonpoint contributions from the watershed include the following constituents:

- water temperature,

- dissolved oxygen,

- ammonia as nitrogen,

- nitrite-nitrate as nitrogen,

- orthophosphate as phosphorus, and

- BOD/organics, comprising

- labileBOD,

- refractory organic nitrogen, 
- refractory organic phosphorus, and

- refractory organic carbon.

All of the above constituents are then modeled within the stream module, along with algal components of phytoplankton and benthic algae. Water quality calibration is an iterative process; the model computations are the integrated result of all the assumptions used in developing the model input and representing the modeled processes. Differences in model computations and observations require the model user to re-evaluate these assumptions, in terms of both the estimated model input and parameters, and consider the accuracy and uncertainty in the observations. At the current time, water quality calibration is more an art than a science, especially for comprehensive simulations of nonpoint, point, and atmospheric sources, and their impacts on instream water quality.

The time period of the water quality calibration coincided with the hydrology calibration period, i.e. 1991-95. However, sufficient water quality data to support a validation were not available; the primary limitation being the lack of adequate point source data for the earlier period. In addition, both resource and data limitations precluded modeling sediment erosion and instream sediment transport and deposition processes, and their impacts on water quality.

The following steps were performed at each of the calibration stations, following the hydrologic calibration and validation, and after the completion of input development for point source and atmospheric contributions:

1. estimate all model parameters, including land use specific accumulation and depletion/removal rates, washoff rates, and subsurface concentrations;

2. tabulate, analyze, and compare simulated nonpoint loadings with expected range of nonpoint loadings from each land use and adjust loading parameters when necessary;

3. calibrate instream water temperature;

4. compare simulated and observed instream concentrations at each of the calibration stations;

5. compare annual nonpoint loading rates with expected values presented in available literature; and

6. analyze the results of comparisons in steps 3,4 , and 5 to determine appropriate instream and/or nonpoint parameter adjustments, and repeat those steps as needed until calibration targets are achieved.

Table 11.3 displays the mean simulated and observed concentrations for the five-year period for all of the water quality stations where calibration was performed. Comparisons could not be made for the constituents where limited or no observed data existed (e.g. BOD and chlorophyll a). Figure 11.2, shown 
Table 11.3 Average annual simulated and observed concentrations.

\begin{tabular}{|c|c|c|c|c|c|c|c|c|c|c|c|c|c|c|c|c|c|c|}
\hline \multirow[b]{3}{*}{ Constituent } & \multicolumn{15}{|c|}{ Average Annual Concentrations ( $\mathrm{mg} / \mathrm{L}$ ) for the Calibration Period (1991-1995) } & & & \\
\hline & \multicolumn{3}{|c|}{$\begin{array}{l}\text { Salmon River nr East } \\
\text { Hampton }\end{array}$} & \multicolumn{3}{|c|}{$\begin{array}{l}\text { Quinnipiac River at } \\
\text { Wallingford }\end{array}$} & \multicolumn{3}{|c|}{$\begin{array}{l}\text { Norwalk River at } \\
\text { Winnipauk }\end{array}$} & \multicolumn{3}{|c|}{$\begin{array}{l}\text { Quinebaug River at } \\
\text { Jewett City }\end{array}$} & \multicolumn{3}{|c|}{$\begin{array}{c}\text { Farmington River at } \\
\text { Tariffville }\end{array}$} & \multicolumn{3}{|c|}{$\begin{array}{l}\text { Housatonic River at } \\
\text { Stevenson }\end{array}$} \\
\hline & Obs. & Sim. & $\begin{array}{r}\text { Ratio } \\
\text { (sample } \\
\text { size) }\end{array}$ & Obs. & Sim. & $\begin{array}{r}\text { Ratio" } \\
\text { (sample } \\
\text { size) }\end{array}$ & Obs. & Sim. & $\begin{array}{r}\text { Ratio }^{*} \\
\text { (sample } \\
\text { size) }\end{array}$ & Obs. & Sim. & $\begin{array}{r}\text { Ratio* } \\
\text { (sample } \\
\text { size) }\end{array}$ & Obs. & Sim. & $\begin{array}{r}\text { Ratio } \\
\text { (sample } \\
\text { size) }\end{array}$ & Oos. & Sim. & $\begin{array}{c}\text { Ratio } \\
\text { (sample } \\
\text { size) }\end{array}$ \\
\hline $\begin{array}{l}\text { Dissolved } \\
\text { Oxygen }\end{array}$ & 10.9 & 10.5 & $0.96(48)$ & 10.4 & 10.3 & $0.99(46)$ & 11.6 & 10.4 & $0.90(97)$ & 10.4 & 10.3 & $0.99(43)$ & 10.2 & 10.8 & $1.06(49)$ & 9.5 & 9.5 & $1.01(41)$ \\
\hline Ammonia as $\mathrm{N}$ & 0.03 & 0.02 & $0.82(43)$ & 0.19 & 0.18 & $0.92(46)$ & 0.04 & 0.04 & $1.18(80)$ & 0.08 & 0.06 & $0.73(42)$ & 0.10 & 0.09 & $0.82(48)$ & 0.06 & 0.06 & $1.10(33)$ \\
\hline $\begin{array}{l}\text { Nitrite-Nitrate as } \\
\mathrm{N}\end{array}$ & 0.22 & 0.27 & $1.21(46)$ & 2.82 & 2.45 & $0.87(46)$ & 0.39 & 0.40 & $1.03(93)$ & 0.44 & 0.37 & $0.84(42)$ & 0.71 & 0.59 & $0.83(49)$ & 0.36 & 0.41 & $1.15(40)$ \\
\hline $\begin{array}{l}\text { Organic } \\
\text { Nitrogen }\end{array}$ & 0.31 & 0.25 & $0.80(30)$ & 0.50 & 0.60 & $1.20(44)$ & 0.33 & 0.28 & $0.86(70)$ & 0.45 & 0.39 & $0.86(40)$ & 0.31 & 0.28 & $0.90(45)$ & 0.33 & 0.28 & $0.84(38)$ \\
\hline Total Nitrogen & 0.53 & 0.51 & $0.97(30)$ & 3.64 & 3.29 & $0.90(44)$ & 0.73 & 0.69 & $0.94(70)$ & 0.96 & 0.80 & $0.83(40)$ & 1.15 & 0.97 & $0.85(45)$ & 0.77 & 0.75 & $0.97(38)$ \\
\hline $\begin{array}{l}\text { Orthophosphate } \\
\text { as } \mathrm{P}\end{array}$ & 0.01 & 0.01 & $0.91(48)$ & 0.32 & 0.36 & $1.10(46)$ & 0.02 & 0.02 & $0.93(94)$ & 0.02 & 0.04 & $1.67(43)$ & 0.07 & 0.13 & $1.90(49)$ & 0.01 & 0.02 & $1.49(32)$ \\
\hline $\begin{array}{l}\text { Organic } \\
\text { Phosphorus }\end{array}$ & 0.02 & 0.02 & $1.30(48)$ & 0.07 & 0.11 & $1.62(46)$ & 0.02 & 0.03 & $1.18(94)$ & 0.03 & 0.04 & $1.23(43)$ & 0.03 & 0.05 & $1.59(49)$ & 0.02 & 0.03 & $1.19(33)$ \\
\hline $\begin{array}{l}\text { Total } \\
\text { Phosphorus }\end{array}$ & 0.02 & 0.03 & $1.35(48)$ & 0.39 & 0.47 & $1.19(46)$ & 0.04 & 0.05 & $1.10(94)$ & 0.06 & 0.08 & $1.44(43)$ & 0.10 & 0.18 & $1.82(49)$ & 0.03 & 0.05 & $1.47(40)$ \\
\hline $\begin{array}{l}\text { Total Organic } \\
\text { Carbon }\end{array}$ & 3.9 & 2.8 & $0.71(45)$ & 4.5 & 4.8 & $1.06(44)$ & 4.0 & 3.2 & $0.81(28)$ & 5.6 & 4.9 & $0.86(41)$ & 3.9 & 3.3 & $0.84(45)$ & 3.8 & 2.9 & $1.06(49)$ \\
\hline
\end{tabular}

"Ratios cal culated from Simulated (computed) and Observed concentrations prior to rounding 
earlier, identifies the water quality gage locations. Daily timeseries plots of observed and simulated values are provided in the study report for all calibration sites and modeled constituents.

Based on the general 'weight-of-evidence' of the simulation results, including the CTWM loading rates, the mean concentrations and ratios (see Table 11.4), and the timeseries comparisons of observed and computed values, the CTWM was determined to be an acceptable representation of the Connecticut watersheds providing loadings to LIS. This evidence indicates that the computed nitrogen and carbon loadings are a 'very good' representation of the observed data, based on the established calibration targets, and that the phosphorus loadings are a 'fair' representation. Clearly improvements can be made to better represent these loadings, especially for phosphorus, but the CTWM in its current form is a sound tool for examining LIS loadings and impacts of alternative watershed scenarios, including future land use changes, increased buildout conditions, and potential BMPs.

Table 11.4 Average and range of computed/observed concentration ratios.

\begin{tabular}{lcc}
\hline Constituent & Average & Range \\
\hline Dissolved Oxygen & 0.99 & $0.90-1.06$ \\
Ammonia as N & 0.93 & $0.73-1.18$ \\
Nitrite-Nitrate as N & 0.99 & $0.83-1.21$ \\
Organic Nitrogen & 0.91 & $0.80-1.20$ \\
Total Nitrogen & 0.91 & $0.83-0.97$ \\
Orthophosphate as P & 1.33 & $0.91-1.90$ \\
Organic Phosphorus & 1.35 & $1.18-1.62$ \\
Total Phosphorus & 1.40 & $1.10-1.82$ \\
Total Organic Carbon & 0.89 & $0.71-1.06$ \\
\hline
\end{tabular}

\subsection{Alternative Watershed Scenarios, Assumptions and Results}

\subsubsection{Scenario Development}

The process of evaluating the impacts of alternative watershed conditions on nutrient loadings to LIS involves (i) establishing a base condition for comparison, (ii) defining the alternative conditions to be simulated, (iii) changing the model to represent those alternatives, and (iv) comparing model results for each alternative to those from the base condition. 
In order to evaluate potential impacts of alternative watershed conditions, including projected future conditions, these conditions, or scenarios, need to be defined in sufficient detail to establish specific quantified changes in the model input, parameters, or watershed configuration (i.e. setup or segmentation characteristics). The CTWM is based on HSPF Version 12 which includes the recent addition of a BMP module specifically designed to allow flexible representation of a wide range of BMPs (Patwardhan et al., 2000; Bicknell et al., 2000). The selected BMPs can be applied to each land use category separately, or in combination with other different land uses, at desired points within a watershed based at the level of detail of the model segmentation. In its current form, the BMP module relies on specification of 'removal efficiencies' to characterize BMP impacts on input loads; future plans include more detailed representation of individual BMPs, including design capabilities.

Discussions with CT DEP staff identified 'future growth' and 'BMP implementation levels' as the primary watershed alternative scenarios to be evaluated under this effort. Seven alternative watershed scenarios were computed, including the base conditions and six combinations of future growth and BMP implementation levels, as follows:

- base conditions,

- $10 \%$ BMP implementation,

- $30 \%$ BMP implementation,

- $50 \%$ BMP implementation,

- 2020 Buildout,

- double (2X) 2020 buildout, and

- double (2X) 2020 buildout plus 50\% BMP implementation.

The levels of BMP implementation correspond to the percent of urban and agricultural areas to be treated or controlled by BMPs within each model segment, and the buildout conditions represent increases in the urban land categories corresponding to projected 2020 conditions. Although these scenarios represent only a subset of potential 'alternative futures' that may be of interest in controlling nitrogen loads, they focus on the key issues of immediate concern. In addition, the CTWM can analyze additional watershed management scenarios.

\subsubsection{Scenario Assumptions}

In order to represent the above scenarios with separate model runs of the CTWM, we needed to define the following:

- land use distributions for each model segment for the 2020 buildout and 2X 2020 buildout scenarios; 
- BMP removal efficiencies for urban and agricultural BMPs for all modeled constituents; and

- model land use affected by the BMP implementation levels $-10 \%$, $30 \%, 50 \%$.

Land use changes for 2020 buildout scenarios

The land use changes for the buildout scenarios were derived from town-bytown population growth projections for 2020. Individual towns were assigned to their subregional basin and associated model segments, and a weighted growth rate was calculated based on the relative land areas of each town so that small or large towns would not have undue impacts. The projected population growth rate was assumed to correspond to the growth in urban land area for each model segment. The resulting increase in urban land segments, including urban pervious, urban impervious, and roads, was taken from the forest and agriculture land segments in relative proportion to their areas within the segment; thus, if urban land increases by $10 \mathrm{~km}^{2}$ and the model segment has a 4:1 ratio of forest to agriculture, then $8 \mathrm{~km}^{2}$ of forest and $2 \mathrm{~km}^{2}$ of agriculture were converted to produce the $10 \mathrm{~km}^{2}$ increase in urban land.

The real growth rates for the subregional basins, corresponding to the reach-based segments, ranged from $0.0 \%$ to $24.3 \%$, with a mean of $7.7 \%$ and a standard deviation of $5.3 \%$; these numbers represent the total increase from 1991-95 conditions to 2020 conditions. The $2 \mathrm{X} 2020$ buildout scenario was produced by simply doubling these growth rates.

\section{BMP removal efficiencies}

To develop appropriate BMP removal efficiencies, the Center for Watershed Protection provided recommendations for selected nutrient and organic constituents for a variety of specific stormwater treatment practices, including infiltration basins, grass filter strips and swales, wetlands, and wet and dry detention ponds (D. Caracao, personal communication, 2000). These values were derived from their National Pollutant Removal Performance Database (Winer, 2000). To supplement this information, we also reviewed BMP efficiency values from the National Stormwater Best Management Practices Database (ASCE and Wright Water Engineers, Inc., 1999) and other modeling studies (Donigian et al., 1997; Donigian et al., 1993) to include both urban and agricultural conditions.

Due to the subregional scale of the modeling (i.e. CTWM model segments), the focus on generalized planning estimates of loads to LIS, and resource limitations, the approach for representing BMPs was to define a 'standard' set of \% removal efficiency factors to represent average removal performance values for typical BMPs applied to both urban and agricultural 
lands. The databases noted above clearly show a wide range of removal efficiency values derived from field studies, depending on a variety of local factors, such as climate, site conditions, soils, design parameters, etc. The removal efficiency values used in the CTWM are shown in Table 11.5.

This same set of removal factors were applied to both urban and agricultural lands because the values in the literature demonstrated such a wide range of efficiencies for practices, for both land use categories. Thus the mean values could equally well represent both conditions.

\section{BMP Implementation Levels}

The three levels of BMP implementation - $10 \%, 30 \%$, and $50 \%$ - were selected to correspond to low, mean, and high levels of nutrient reduction. This is implemented in the CTWM by applying the standard set of removal efficiencies to the loads generated by the corresponding fractions of both urban and agricultural lands within each model segment. That is, a 10\% BMP implementation means that $10 \%$ of the urban and agricultural land within a model segment will have its nonpoint source loads reduced by the removal efficiencies listed in Table 11.5. In partial support of these levels, the $50 \%$ implementation level is consistent with the LISS Phase III management goal being incorporated into the LIS TMDL analysis (NYSDEC and CT DEP, 1999).

The same implementation levels are used for both urban and agricultural lands so that a general relationship (i.e. simplified model or spreadsheet) might be developed between BMP implementation and load reduction percentages.

Table 11.5 BMP removal efficiency values used in the CTWM.

\begin{tabular}{cc}
\hline Constituent & Removal Efficiency (\%) \\
\hline BODu & $40 \%$ \\
$\mathrm{NO}_{\mathrm{x}}$ & $35 \%$ \\
$\mathrm{NH}_{3}$ & $45 \%$ \\
$\mathrm{PO}_{4}$ & $50 \%$ \\
Organic $\mathrm{N}$ & $55 \%$ \\
Organic $\mathrm{P}$ & $55 \%$ \\
Organic C & $55 \%$ \\
\hline
\end{tabular}

\subsubsection{LIS Nutrient Loads under Alternative Watershed Scenarios}

The CTWM was run for each of the six scenarios for the five-year 1991-95 time period, and scenario results were tabulated for the average annual nonpoint source and total loads for Total N, Total P, and TOC for each management zone and for the entire State, along with the $\%$ change from the base condition. These 
results include the impacts of the attenuation factors for the Connecticut River, Housatonic River, and Quinnipiac River in reducing the input load (i.e. assimilation) during delivery to LIS. A spreadsheet was developed to tabulate the CTWM scenario results, impose the attenuation factors for the appropriate management zones, calculate the \% changes from the base conditions, and generate the summarized results shown in Table 11.6.

Table 11.6 Percent change in average annual nutrient loads (NPS and total) delivered to LIS for each of the CTWM scenarios.

\begin{tabular}{|c|c|c|c|c|c|c|}
\hline \multirow[t]{2}{*}{ Scenario } & \multicolumn{2}{|c|}{ Total Nitrogen } & \multicolumn{2}{|c|}{ Total Phosphorus } & \multicolumn{2}{|c|}{$\begin{array}{c}\text { Total Organic } \\
\text { Carbon }\end{array}$} \\
\hline & NPS & Total & NPS & Total & NPS & Total \\
\hline $\begin{array}{l}10 \% \text { BMP } \\
\text { Implementation }\end{array}$ & -1.78 & -0.48 & -2.11 & -0.39 & -2.78 & -1.07 \\
\hline $\begin{array}{l}30 \% \text { BMP } \\
\text { Implementation }\end{array}$ & -5.70 & -1.54 & -6.62 & -1.23 & -8.99 & -3.46 \\
\hline $\begin{array}{l}50 \% \text { BMP } \\
\text { Implementation }\end{array}$ & -9.62 & -2.59 & -11.13 & -2.07 & -15.20 & -5.85 \\
\hline 2020 Buildout & 1.38 & 0.37 & 1.38 & 0.26 & 1.72 & 0.66 \\
\hline $\begin{array}{l}\text { Double (2X) } \\
2020 \text { Buildout }\end{array}$ & 2.56 & 0.69 & 2.53 & 0.47 & 3.09 & 1.19 \\
\hline $\begin{array}{l}\text { Double }(2 X) \\
2020 \text { Buildout plus } \\
50 \% \text { BMP } \\
\text { Implementation }\end{array}$ & -7.90 & -2.10 & -9.40 & -1.70 & -13.40 & -5.20 \\
\hline
\end{tabular}

Based on the CTWM scenario results, the following observations and conclusions may be made:

- The statewide changes for the three BMP implementation scenarios become significant at the $30 \%$ implementation level, with nonpoint source (NPS) reductions ranging from 5\% to $9 \%$. At the $50 \%$ implementation level, NPS reductions range from $9 \%$ to $15 \%$ with changes up to $21 \%$ for an individual management zone; the total reductions are less, ranging from $2 \%$ to $6 \%$, due to the point source contributions. However, it is important to realize that the BMPs in these scenarios were implemented only on urban and agricultural lands; these two categories only represent a combined $30 \%$ of the entire land area.

- NPS reductions are highest for total organic carbon followed by total phosphorus and total nitrogen, for the BMP implementation scenarios. This ordering for the NPS loads is likely the end result of the combined effects of the removal efficiencies, the loading rates, delivery processes, and sources. 
- The buildout scenarios show that nonpoint loading effects of future urban growth are almost linear, i.e. the $\%$ changes for the 2Xbuildout are just about twice those of the buildout scenario. The absolute values of these changes are small because the growth only affects the urban model segments (both pervious and impervious), which represent about $16 \%$ of the total area.

- Figure 11.3 shows the relationship between the percent reduction in both NPS and total loads delivered to LIS and the percent BMP implementation, derived from the values in Table 11.6. Based on the $10 \%, 30 \%$, and $50 \%$ BMP implementation scenarios, the relationship is almost linear; as expected the NPS plots are considerably higher than the total plots. It is interesting to note that the ordering of the plots changes between NPS and total; the TP plot is between the TOC and TN plots for NPS loads, but it is the lowest of the plots for the total loads; this reflects the larger relative contribution from point sources for TP. This simple graph can be used to estimate impacts of alternative implementation levels for BMPs for urban lands and agriculture.

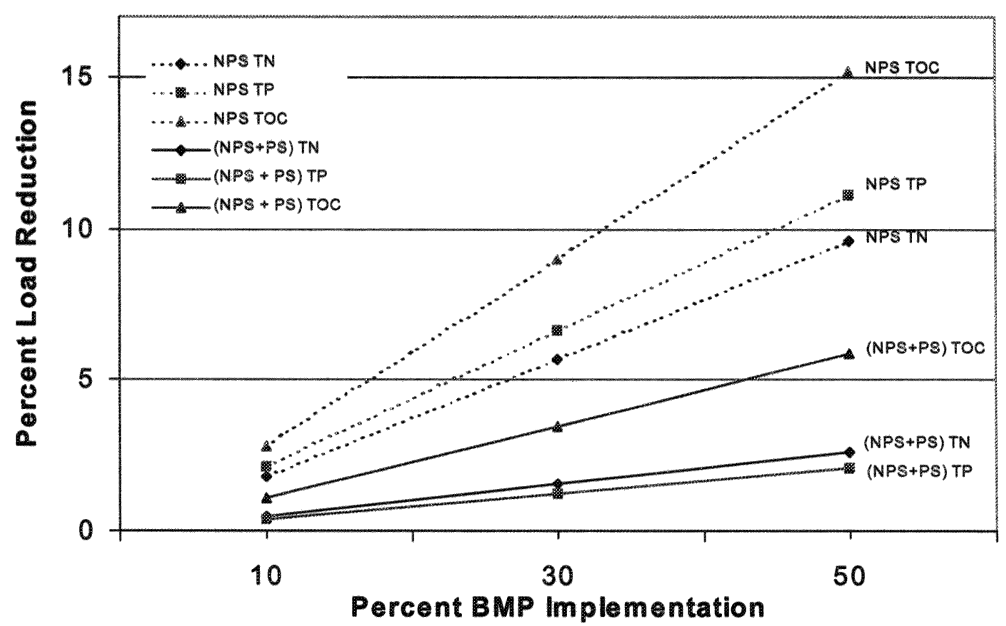

Figure 11.3 Relationship between percent reduction in nonpoint and total loads delivered to LIS and percent BMP implementation on urban and agricultural land.

- If higher levels of nonpoint source nutrient reductions are needed to meet TMDL or nitrogen control targets, the potential alternatives include:

- increasing the percent of area treated (i.e. the BMP implementation level), 
- increasing the percent removal efficiencies, but this has physical and technological limits, or

- expanding BMPs to other land uses, with forest lands being the obvious target.

In meeting the study objectives, the CTWM, developed in this effort, can serve as a tool for the ongoing TMDL process by providing the framework for evaluating the impacts of alternative management options, analyzing potential tradeoffs between point and nonpoint loads, and performing the periodic reviews and revisions required by the regulation.

\section{References}

AQUA TERRA Consultants and HydroQual, In., 2001. Modeling Nutrient Loads to Long Island Sound from Connecticut Watersheds, and Impacts of Future Buildout and Management Scenarios. Prepared for Connecticut Department of Environmental Protection, Hartford, CT.

ASCE and Wright Water Engineers. 1999. National Stormwater Best Management Practices (BMP) Database. Version 1.0. Prepared by Urban Water Resources Research Council of ASCE, and Wright Water Engineers, Inc., Urban Drainage and Flood Control District, and URS Greiner Woodward Clyde, in cooperation with U. S. EPA, Office of Water, Washington, D.C. User's Guide and CD.

Bicknell, B.R., J.C. Imhoff, J.L. Kittle Jr., A.S. Donigian, Jr, and R.C. Johanson. 1997. Hydological Simulation Program - FORTRAN, User's Manual for Version 11. EPA/600/R-97/080. U.S. EPA, National Exposure Research Laboratory, Athens, GA. 763 p.

Bicknell, B.R., J.C. Imhoff, J.L. Kittle Jr., A.S. Donigian, Jr., T.H. Jobes, and R.C. Johanson. 2000. (Draft) Hydological Simulation Program - FORTRAN, User's Manual for Version 12. U.S. EPA, National Exposure Research Laboratory, Athens, GA.

Donigian, A.S. Jr., R.V. Chinnaswamy, and D.C. Beyerlein. 1993. Surface Water Exposure Assessment for Walnut Creek, Iowa - Preliminary Application of the U.S. EPA HSPF to Assess Agrichemical Contributions and Impacts. Prepared by AQUA TERRA Consultants, Mountain View, CA. Prepared for U.S. EPA, Athens, GA under Contract No. 68-C0-0019.

Donigian, A.S. Jr., B. R. Bicknell, and J.C. Imhoff. 1995. Chapter 12. Hydrological Simulation Program - FORTRAN. In: Computer Models of Watershed Hydrology. V.P. Singh (ed). Water Resources Publications, Highland Ranch, CO. pp. $395-442$.

Donigian, A.S. Jr., R.V. Chinnaswamy, and T.H. Jobes. 1997. Conceptual Design of Multipurpose Detention Facilities for both Flood Protection and Nonpoint Source Pollution Control. Draft Final Report. Prepared for Santa Clara Valley Water District, San Jose, CA. 151 p.

Donigian, Jr., A.S., 2000. HSPF Training Workshop Handbook and CD. Lecture \#19. Calibration and Verification Issues, Slide \#L19-22. EPA Headquarters, Washing- 
ton Information Center, 10-14 January, 2000. Presented and prepared for U.S. EPA, Office of Water, Office of Science and Technology, Washington, D.C.

HydroQual, Inc. 1996. Water Quality Modeling Analysis of Hypoxia in Long Island Sound Using LIS 3.0. Conducted by direction of the Management Committee of the Long Island Sound Study through a contract with the New England Interstate Water Pollution Control Commission.

HydroQual, Inc. 1999. Newtown Creek Water Pollution Control Project - East River Water Quality Plan. System-Wide Eutrophication Model (SWEM). Prepared under subcontract to Greeley and Hansen, New York, NY.

Kittle, J.L. Jr., A. M. Lumb, P.R. Hummel, P.B. Duda, and M.H. Gray. 1998. A Tool for the Generation and Analysis of Model Simulation Scenarios for Watersheds (GenScn). Water Resources Investigation Report 98-4134. U.S. Geological Survey, Reston, VA. 152 p.

Linker, L.C., G.E. Stigall, C.H. Chang, and A.S. Donigian, Jr. 1993. The Chesapeake Bay Watershed Model. Prepared by U.S. EPA, Chesapeake Bay Program Office, Annapolis, MD.

Linker, L.C., C.G. Stigall, C.H. Chang, and A.S. Donigian. 1996. Aquatic Accounting: Chesapeake Bay Watershed Model Quantifies Nutrient Loads. Water Env. \& Tech. Vol. 8(1):48-52.

Lumb, A.M., R.B. McCammon, and J.L. Kittle, Jr. 1994. Users Manual for an Expert System (HSPEXP) for Calibration of the Hydrological Simulation Program FORTRAN. Water-Resources Investigations Report 94-4168, U.S. Geological Survey, Reston, VA. 102 p.

New York State Department of Environmental Protection and Connecticut Department of Environmental Protection 1999. DRAFT - Total Maximum Daily Load Analysis to Achieve Water Quality Standards for Dissolved Oxygen in Long Island Sound. Prepared in Conformance with Section 303(d) of the Clean Water Act and the Long Island Sound.

Patwardhan, A. S., A. S. Donigian, Jr., J. L. Kittle, Jr., and T. H. Jobes. 2000. Development and Application of New Tools within BASINS Model to Georgia Watersheds. Watershed Management 2000 Conference. Vancouver, BC, Canada, July 9-12, 2000. CD-ROM Proceedings.

Winer, R. 2000. National Pollutant Removal Database for Stormwater Treatment Practices, 2nd Edition. Center for Watershed Protection, Ellicott City, MD. Prepared for U. S. EPA, Office of Science and Technology, in association with Tetra Tech, Inc. Fairfax, VA. 